\title{
Grain Growth Model of Ultra-Fine Grain AZ80 Magnesium Alloy Multi- Directionally Forged During the Isothermal Heating Process
}

\author{
Jinlong ZHANG ${ }^{1,2}{ }^{*}$, Hui XIE ${ }^{1,2}$, Ying MA ${ }^{1,2}$, Shiping TAO ${ }^{1,2}$, Kun ZHAO $^{1,2}$, \\ Weigang WU ${ }^{1,2}$
}

${ }^{1}$ State Key Laboratory of Advanced Processing and Recycling of Non-Ferrous Metals, Lanzhou University of Technology,
Lanzhou 730050, China
${ }^{2}$ School of Materials Engineering, Xi'an Aeronautical University, Xi'an Shaanxi 710077, China
crossref http://dx.doi.org/10.5755/j01.ms.25.2.19093

Received 22 June 2017; accepted 20 February 2018

\begin{abstract}
This paper takes the ultra-fine grain AZ80 magnesium alloy multi-directionally forged as the research object. We observe its heating behavior at $673 \mathrm{~K}$ with an optical microscope, analyze the grain size distribution, and the change of average grain size and hardness with different heating time, study the effect of heating time on the grain size change of ultra-fine grain AZ80 magnesium alloy, deduce and verify the grain growth model of ultra-fine grain AZ80 magnesium alloy during its heating process. The research results show that the 24-pass multi-directional forging can make ultra-fine grain AZ80 magnesium alloy of an average grain size of $0.73 \mu \mathrm{m}$. When ultra-fine grain AZ80 magnesium alloy is isothermally heated at $673 \mathrm{~K}$, its average grain size grows continuously as time extends. Its average grain size and hardness fall into two stages as the heating time changes, namely rapid grain growth stage and stable grain growth stage. If the heat preservation time is less than $300 \mathrm{~s}$, the average grain size grows rapidly as temperature rises; When the heat preservation time reaches $300 \mathrm{~s}$, the grain growth speed will be stable. A grain growth model is established for AZ80 magnesium alloy, which is $D^{2.8932}=D 0^{2.8932}+4.09086 \times 10^{-3} t^{1.6284}$ under the conditions of isothermal heating, whose computed result well coincides with the measured value.

Keywords: multi-directional forging, ultra-fine grain, AZ80 magnesium alloy, isothermal heating, grain growth.
\end{abstract}

\section{INTRODUCTION}

As the lightest structural metallic materials in current practical applications, magnesium and its alloy have high specific strength and specific stiffness superior to steel and aluminum, excellent thermal conductance and machining properties, and can be easily recycled. They can be used in 3C, automobile, aerospace and other fields, and are attracting more and more attention [1-3]. But the frequently used magnesium alloy has a close-packed hexagonal (HCP) crystal structure, with only two independent slip systems at room temperature, and the disadvantages of poor plasticity and being difficult to be molded and processed. Therefore, in order to make magnesium alloy applied more extensively, it is one of the research hotspots of wrought magnesium alloy to find a suitable process to improve its plasticity. Among them, as an important means to improve the plasticity of magnesium alloy, grain refining not only can improve its plasticity to a certain extent, but also can enhance its strength [4-5]. When grain size is refined to the ultra-fine grain state of submicron, magnesium alloy has superplasticity even at room temperature [6-7]. In the wrought magnesium alloy field, equal channel angular pressing (ECAP) [8, 9], multi-directional forging (MDF) $[10,11]$, accumulative roll-bonding (ARB) $[12,13]$ and other severe plastic deformation modes are mainly used to make magnesium alloy of fine grains microstructure at the current stage.

\footnotetext{
* Corresponding author. Tel.: +86-15094092813.

E-mail address: zjl24931@163.com (J. Zhang)
}

The plastic working structure of metallic materials is usually in the nonequilibrium state, especially there is often multiple heating deformation during the severe plastic deformation process. The temperature variation between multiple heating is bound to cause the change in material microstructure, while the most obvious change is the growth of material grain. Grain growth inside the workpiece is a negative phenomenon, which will cause the reduction of mechanical properties and useful life of materials. Some scholars have conducted extensive studies on the grain growth phenomenon of different materials and established different growth models [14-21].

However, studies on the grain growth rules of AZ80 magnesium alloy in the hot working process are rarely reported. Since the structure heat stability of fine grain magnesium alloy materials is of great importance to their engineering application, this paper will take ultra-fine grain AZ80 magnesium alloy after multi-directional forging deformation as the research object, and establish a mathematical model which describes the grain growth rules of ultra-fine grain AZ80 magnesium alloy under isothermal conditions based on existing theory models to provide theoretical basis for hot working technology and subsequent heat treatment process to control and regulate the grain size of magnesium alloy, thus getting magnesium alloy with the required mechanical properties.

\section{EXPERIMENT}

Material used in the experiment is commercial AZ80 magnesium alloy sheet with a thickness of $15 \mathrm{~mm}$. Its chemical component (mass fraction, \%) is $\mathrm{Al} 8.48$, 
Zn 0.55, Mn 0.32, Cu 0.003, Si 0.05, Fe 0.003 and $\mathrm{Mg}$ of the remaining fraction. The sheet is cut into cuboid sample of $18 \mathrm{~mm} \times 16.5 \mathrm{~mm} \times 15 \mathrm{~mm}$ with wire electrode, and its height is the same as rolling direction.
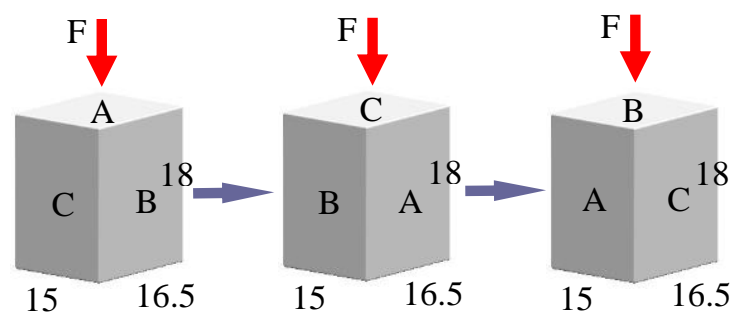

Fig. 1. Schematic diagram of multi-directional forging

The forging experiment is conducted on a hydraulic testing machine with a controllable deformation speed. Firstly, the sample is heated in a resistance furnace at $673 \mathrm{~K}$ for 5 minutes, then it is multi-directionally forged at a deformation velocity of $9 \mathrm{~mm} / \mathrm{s}$, and the initial forging axis is parallel to the rolling streamline. As is shown in Fig. 1., the forging direction changes successively following the three vertical directions, with a true strain of $\Delta \varepsilon=0.18$ for each pass. After each pass being finished, the sample is reheated at $673 \mathrm{~K}$ for 5 minutes, and then be forged for the next pass. When the deformation reaches the set value, stop deforming and conduct water quenching.

The sample forged is cut into $n$ equal parts, and is isothermally heated at $673 \mathrm{~K}$, with a heat preservation time of $60 \mathrm{~s}, 120 \mathrm{~s}, 210 \mathrm{~s}, 300 \mathrm{~s}, 600 \mathrm{~s}, 1200 \mathrm{~s}, 1800 \mathrm{~s}, 3600 \mathrm{~s}$, $5400 \mathrm{~s}, 7200 \mathrm{~s}$ and $9000 \mathrm{~s}$ respectively. Then the heated sample is mechanically lapped and polished, and is corroded with the mixed solution formulated with $1 \mathrm{~g}$ oxalic acid, $1 \mathrm{~mL}$ acetic acid, $1 \mathrm{~mL}$ nitric acid and $100 \mathrm{~mL}$ distilled water. Its microscopic structure is analyzed with an OLYMPUS-GX71 optical microscope, and the average grain diameter with Image Pro Plus image analysis software is determined.

\section{RESULTS AND ANALYSIS}

\subsection{Microscopic structure}

The microscopic structure of the sample before and after multi-directional forging is as shown in Fig. 2. The microscopic structure of the original sheet metal is as shown in Fig. 2 a, which is coarse with an average grain size of about $48.5 \mu \mathrm{m}$. The sample cut with wire electrode is conducted 24-pass multi-directional forging after being heated, and its accumulated strain capacity $\Sigma \varepsilon$ reaches 4.32 at this moment. Quenching of the deformed sample is immediate, and the deformed microstructure reserved is as shown in Fig. 2 b. There is even fine grain structure formed in the sample with an average grain size of $0.73 \mu \mathrm{m}$. According to Fig. 2, multi-directional forging makes the grain refined intensively.

When the sample has an accumulated true strain capacity of 4.32, its microscopic structure after being heated at $673 \mathrm{~K}$ under different time conditions is as shown in Fig. 3. According to Fig. 3, when its heat is preserved for $60 \mathrm{~s}$ at $673 \mathrm{~K}$, the deformed microstructure generated after forging starts to produce static recrystallization with thermal activation, and some grains grow, but the static recrystallization is incomplete and deformed microstructure still exists, and the average grain size increases to $0.96 \mu \mathrm{m}$. As the extension of heating time, the original forging deformation microstructure is gradually replaced by new globular grains. The growth phenomenon of a little individual grains emerges when the heat is preserved for $120 \mathrm{~s}$, as is shown in the dotted line circle of Fig. 2 b, and the average grain size grows to $2.01 \mu \mathrm{m}$. When its heat is preserved for $210 \mathrm{~s}$, the heated microscopic structure is as shown in Fig. 2 c, which shows obvious grain growth in comparison with Fig. 2 b, and the globular grain grows to $4.95 \mu \mathrm{m}$. When the heat preservation time exceeds $210 \mathrm{~s}$, with the rise of temperature, the deformed microstructure in the material disappears completely and the recrystallization finishes. The grain growth will slow down for reduced driving force, and it is a stable coarsening process, generating equiaxed grain structure completely recrystallized as is shown in Fig. $2 \mathrm{c}-\mathrm{j}$.

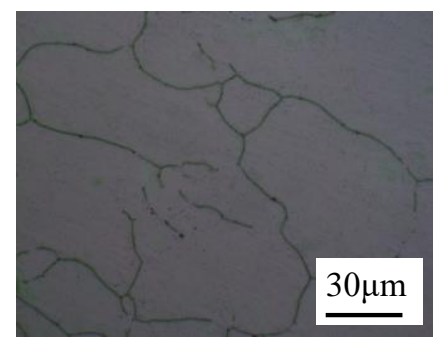

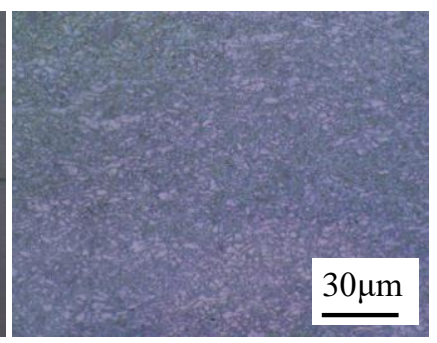

Fig. 2. Microscopic structure of AZ80 magnesium alloy before and after forging deformation: a-microscopic structure of AZ80 sheet metal; $b$-microscopic structure of AZ80 sheet metal after 24-pass forging

The relationship between the change of average grain size and hardness of ultra-fine grain AZ80 magnesium alloy with different heat treatment time is as shown in Fig. 4. According to Fig. 4, when $t$ is less than $300 \mathrm{~s}$, the average grain size and hardness change rapidly as temperature varies; when $t$ is more than $300 \mathrm{~s}$ but less than $9000 \mathrm{~s}$, the average grain size and hardness change relatively slowly as temperature varies, the hardness decreases with the increase of average grain size, and the speed decrease trend also coincides with the growth speed trend of average grain size, which basically conforms to Hall-Petch relation. The value $300 \mathrm{~s}$ is the change demarcation point of average grain size and hardness, and it divides the heating process of ultra-fine grain AZ80 magnesium alloy into two zones. Zone I is the rapid growth process of recrystallized grain, and Zone II is the normal grain growth process.

\subsection{Kinetic study on grain growth}

It is essential to establish a mathematical model for studying the behavior of AZ80 magnesium alloy grain growth. According to relevant documents, the grain growth trend of magnesium alloy and austenite are basically the same, so this paper adopts a relatively universal austenite grain growth model to explore the growth model of magnesium alloy grain. 


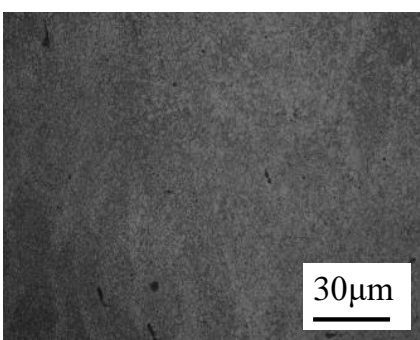

$\mathrm{a}$
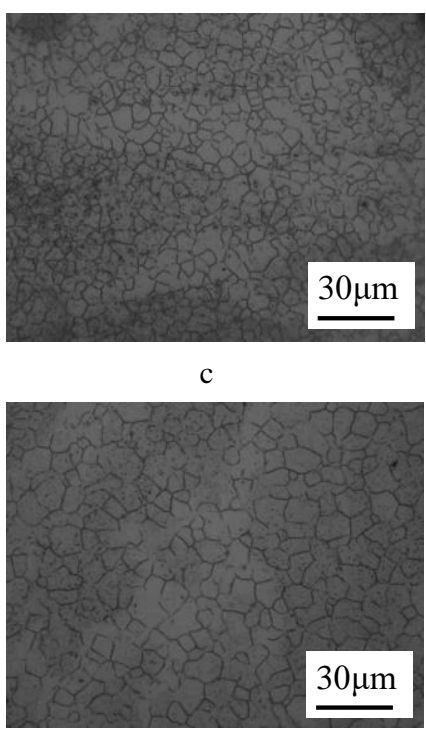

$\mathrm{e}$

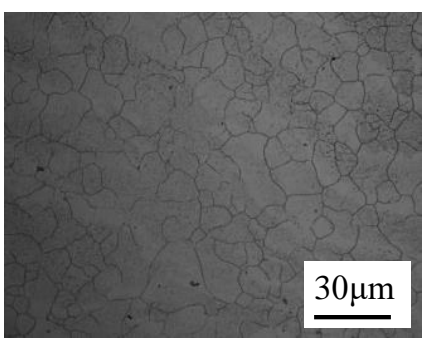

g

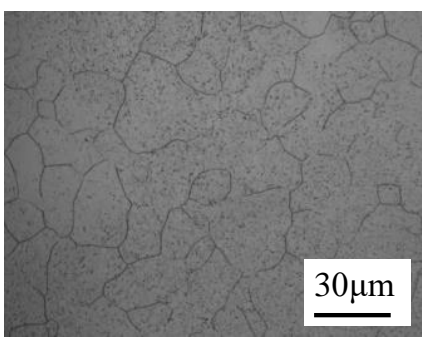

i

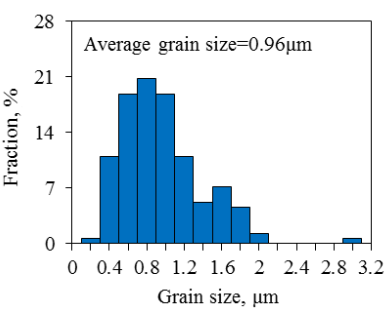

a1

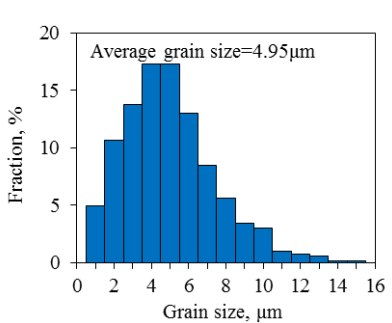

$\mathrm{c}_{1}$

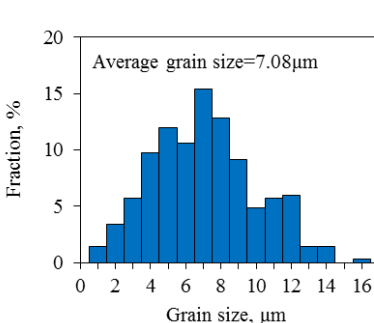

$\mathrm{e}_{1}$

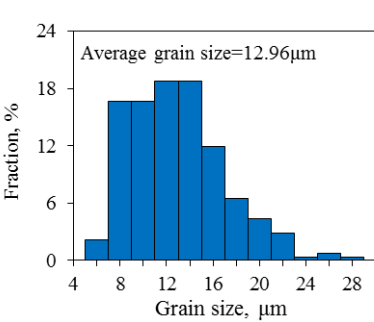

$g_{1}$

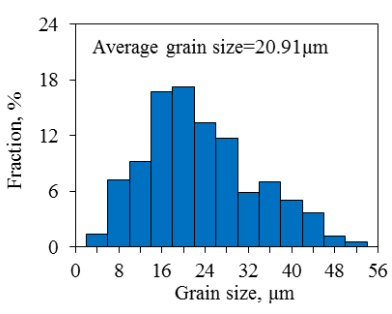

$i_{1}$

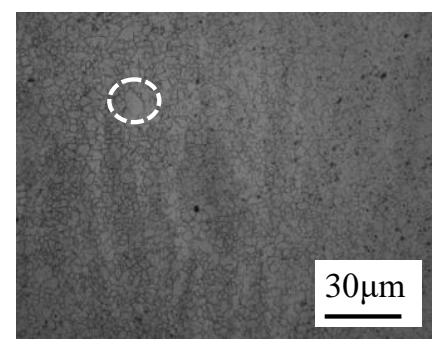

b

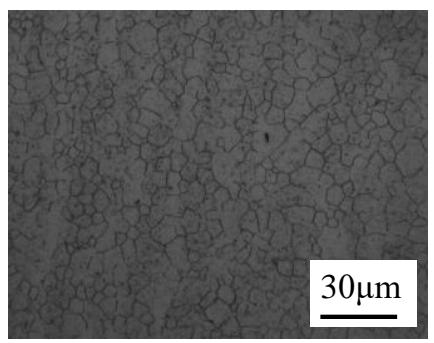

d

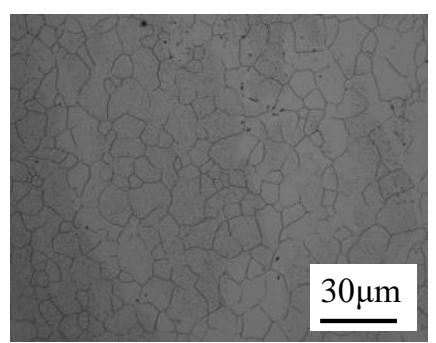

f

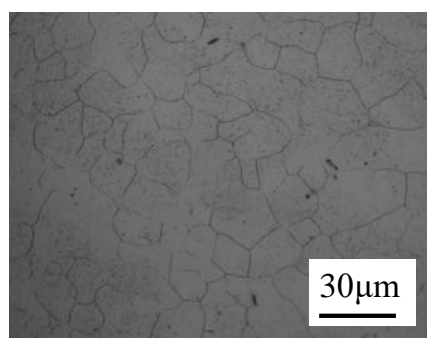

h

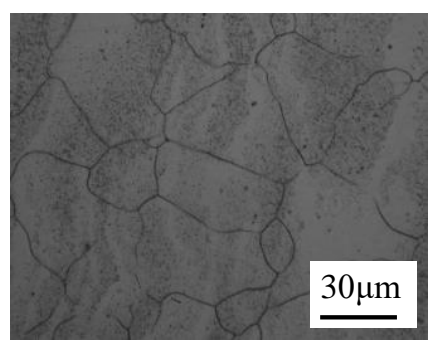

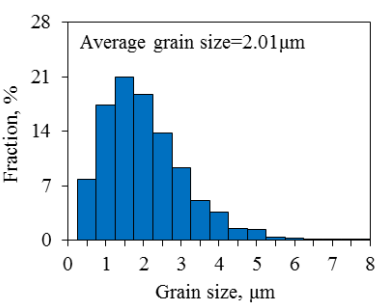

$b_{1}$

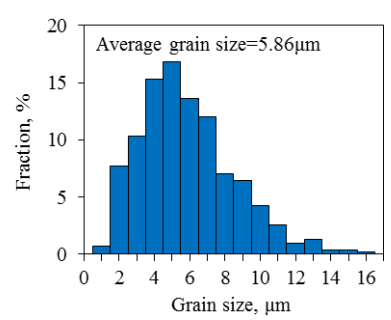

$\mathrm{d}_{1}$

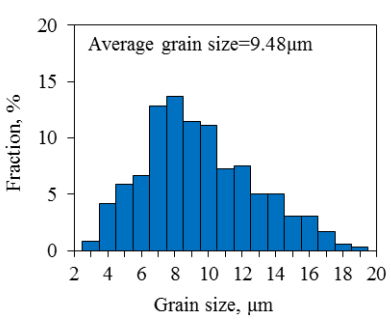

$f_{1}$

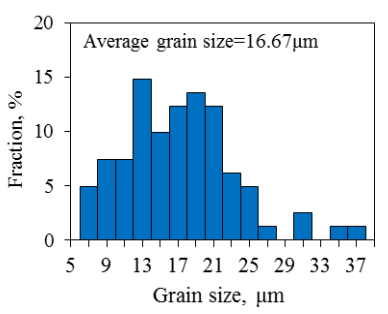

$\mathrm{h}_{1}$

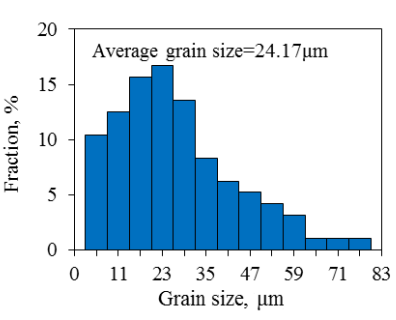

j1

Fig. 3. The microscopic structure $(\mathrm{a}-\mathrm{j})$ and corresponding recrystallized grain size distribution $\left(\mathrm{a}_{1}-\mathrm{j}_{1}\right)$ of the multi-directionally forged AZ80 sample with an accumulated true strain capacity of 4.32 after different heat preservation time at $673 \mathrm{~K}$, where the heat preservation times: a-60 s; b-120 s; c-210 s; d-300; e-600 s; f-1800 s; g-3600 s; h-5400 s; i-7200 s; j-9000 s

The two models presented by Sellars [22] and Anelli [23] respectively, namely Eq. 1 and Eq. 2, are usually adopted to forecast the austenite grain growth model during the heating process.

$D_{t}^{n}=D^{n}+A t \exp [-Q /(R T)] ;$

$D_{t}^{n}=B t^{m} \exp [-Q /(R T)]$,

where $D_{t}$ refers to the grain size at $t(\mu \mathrm{m}), D_{0}$ refers to the initial average grain size $(\mu \mathrm{m}), T$ refers to heating temperature $(\mathrm{K}), t$ refers to heat preservation time (s), $R$ refers to molar gas constant $\left(8.314 \mathrm{~J} \cdot \mathrm{mol}^{-1} \cdot \mathrm{K}^{-1}\right), Q$ refers to the activation energy for grain growth in the heat preservation process $\left(\mathrm{J} \cdot \mathrm{mol}^{-1}\right)$, and $A, B, n$ and $\mathrm{m}$ are constants, which depend on experimental data and are related to material type.

Based on overall consideration of Eq. 1 and Eq. 2, a relatively reasonable model is established to describe the grain growth rules of AZ80 magnesium alloy, which is expressed with Eq. 3: 


$$
D_{t}^{n}=D_{0}{ }^{n}+K_{0} t^{m} \exp [-Q / R T]
$$

where $K_{0}$ and $R$ are constants, and $Q$ is also constant on the precondition of a constant $T$, so Eq. 3 can be abbreviated as Eq. 4.

$D_{t}^{n}=D_{0}^{n}+K t^{m}$

where

$$
K=K_{0} t^{m} \exp [-Q / R T]
$$

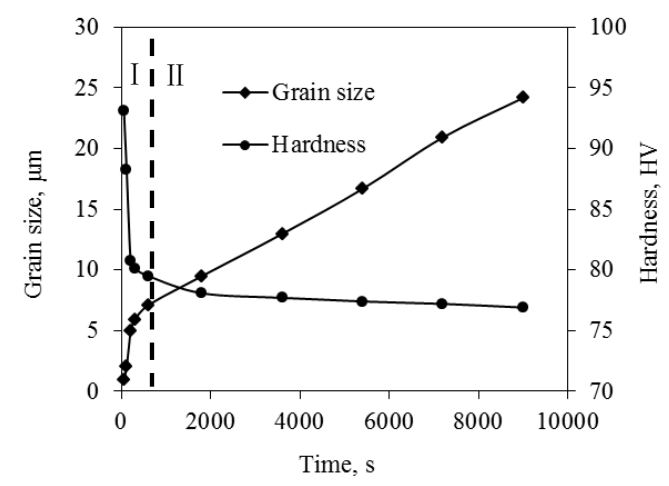

Fig. 4. The relationship between the change of average grain size and hardness with different heat treatment time

To determine the constants in the model, Eq. 6 can be obtained from Eq. 5:

$\ln \left(D_{t}{ }^{n}-D_{0}{ }^{n}\right)=\ln K+m \ln t$.

There are three unknown quantities $n, K$ and $m$ in Eq. 4 which cannot be directly determined by linear fitting, so the value of $n$ will be given in advance in this paper, assume that $n$ is equal to $0.5,1.0,1.5,2.0,2.5,3.0,3.5,4.0$, 4.5 and 5.0. The values of $K, m$ and their respective error value are determined by experimental data fitting, and taking the quadratic sum of the error as the function of $n$, while the minimal quadratic sum of regression error as the optimal object. The changing curve of error quadratic sum $y(n)$ with different values of $n$ is shown in Fig. 5. The changing situation of error quadratic sum $y(n)$ obtained by point fitting of experimental data with different values of $n$ is as shown in Eq. 6.

$$
y(n)=3.54332+14.39604 n-17.51673 n^{2}+7.50361 n^{3}-
$$$$
1.61684 n^{4}-0.18964 n^{5}-0.00927 n^{6} \text {. }
$$

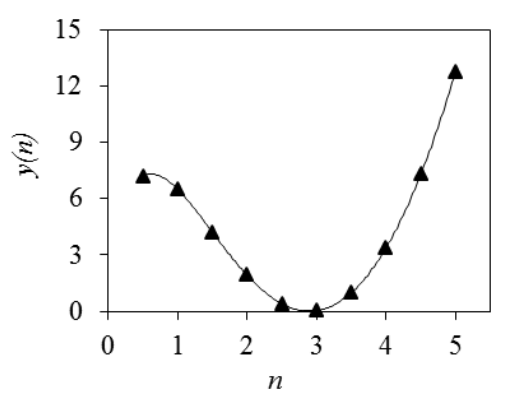

Fig. 5. The relationship between error quadratic sum $y(n)$ and experimental coefficient $n$

The extreme value of Eq. 7 is found, when $n$ is equal to 2.8932 , the minimum value of function $y(n)$ is obtained. Substituting $n=2.8876$ into Eq. 6 and recalculating the value of $K$ and gives $m$ is equal to 1.8341 while $K$ is equal to $4.09086 \times 10^{-3}$. Then the grain growth model of ultra-fine grain AZ80 magnesium alloy can be obtained, as is shown in Eq. 8.

$D^{2.8932}=D_{0}^{2.8932}+4.09086 \times 10^{-3} t^{1.6284}$

To verify the accuracy of grain growth model deduced above, Fig. 6 provides a contrast analysis diagram of grain size calculated from this model at different heat preservation time and actual measured result. According to the figure, the computed result is basically identical to the experimental result, and the determination coefficient of its predicted value and experimental value is 0.963 , which shows this model can reflect the grain growth rules of ultra-fine grain AZ80 magnesium alloy.

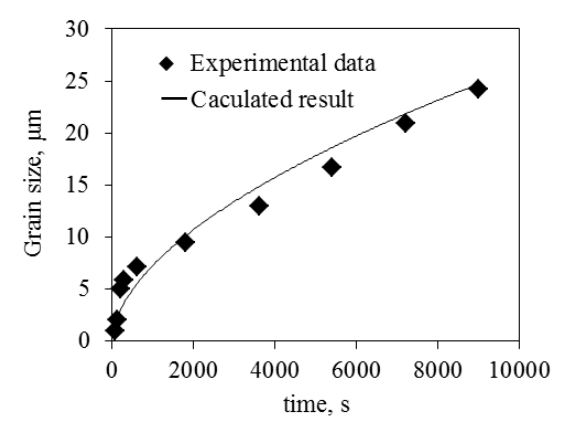

Fig. 6. Comparison of experimental value and computed value of the grain size under different heat treatment

\section{CONCLUSIONS}

1. Multi-directional forging intensively refines the microscopic structure of AZ80 magnesium alloy sheet metal, and its average grain size reduces from $48.5 \mu \mathrm{m}$ to $0.73 \mu \mathrm{m}$, the former is 66.4 times of the latter. Ultra-fine grain structure is thereby obtained.

2. The average grain size of ultra-fine grain AZ80 magnesium alloy grows continuously with the extension of heating time when it is heated at $673 \mathrm{~K}$. When the heat preservation time is less than $300 \mathrm{~s}$, fine grain component rapidly reduces as temperature rises, and grain grows obviously; When the heat preservation time reaches $300 \mathrm{~s}$, the growth rate of grain tends to be stable.

3. According to the changing curve of average grain size and hardness with different heating temperatures, the heating process shows two obvious stages, namely rapid grain growth stage and stable grain growth stage.

4. Establish a grain growth kinetic equation for AZ80 magnesium alloy which is $\mathrm{D}^{2.8932}=\mathrm{D}_{0}{ }^{2.8932}+4.09086 \times 10^{-3} t^{1.6284}$ under the conditions of isothermal heating, whose computed result coincides well with the actual measured value.

\section{Acknowledgments}

This work was supported by the fund of The State Key Laboratory of advanced Processing and Recycling of Nonferrous Metals, Lanzhou University of Technology (Program no. SKLAB02015007), The Project Supported by Natural Science Basic Research Plan in Shaanxi Province of China (Program No. 2014JM2-5050), and 
Scientific Research Program Funded by Shaanxi Provincial Education Department (Program No. 15JK1377).

\section{REFERENCES}

1. Wang, Y.N., Huang, J.C. The Role Of Twinning and Untwining in Yielding Behavior in Hot-Extruded Mg-Al-Zn Alloy Acta Materialia 55 (3) 2007: pp. 897-905. https://doi.org/10.1016/j.actamat.2006.09.010

2. Nie, K.B., Deng, K.K., Wang, X.J., Xu, F.J., Wu, K., Zheng, M.Y. Multidirectional Forging of AZ91 Magnesium Alloy and Its Effects on Microstructures and Mechanical Properties Materials Science \& Engineering A 624 2007: pp. $157-168$.

https://doi.org/10.1016/j.msea.2014.11.076

3. Zhang, J., Huang, H., Yang, C.B. Effects of Hot Ring Forging on Microstructure, Texture and Mechanical Properties of AZ31 Magnesium Alloy Materials Science \& Engineering A 679 2017: pp. 20-27. https://doi.org/10.1016/j.msea.2016.10.024

4. Yang, X.Y., Miura, H., Sakai, T. Recrystallization Behavior of Fine-Grained Magnesium Alloy after Hot Deformation Transactions of Nonferrous Metals Society of China 17 (6) 2007: pp. 1139-1142. https://doi.org/10.1016/S1003-6326(07)60239-8

5. Vinogradov, A., Orlov, D., Danyuk, A., Estrin, Y. Effect of Grain Size on The Mechanisms of Plastic Deformation in Wrought Mg-Zn-Zr Alloy Revealed by Acoustic Emission Measurements Acta Materialia 61 (6) 2013: pp. $2044-2056$. https://doi.org/10.1016/j.actamat.2012.12.024

6. Li, J.L., Wu, D., Yang, Q.B., Chen, R.S. Superplasticity of Multi-Directional Impact Forged Mg-Gd-Y-Zr Alloy Journal of Alloys \& Compounds 672 2016: pp. 27-35. https://doi.org/10.1016/j.jallcom.2016.02.132

7. Zhang, Z.R., Xing, J., Yang, X., Miura, H., Sakai, T. Anisotropy of Low Temperature Superplasticity of Fine Grained Magnesium Alloy AZ31 Processed by Multidirectional Forging Materials Science \& Technology 25 (12) 2009: pp. 1442-1447.

http://dx.doi.org/10.1179/174328408X339279

8. Gopi, K.R., Nayaka, H.S., Sahu, S. Investigation of Microstructure and Mechanical Properties of ECAPProcessed AM Series Magnesium Alloy Journal of Materials Engineering \& Performance 25 (9) 2016: pp. $1-9$.

https://doi.org/10.1007/s11665-016-2229-7

9. Amouyal, Y, Divinski, S.V., Klinger, L., Rabkin, E. Grain Boundary Diffusion and Recrystallization in Ultrafine Grain Copper Produced by Equal Channel Angular Pressing Acta Materialia 56 (19) 2008: pp. 5500-5513. https://doi.org/10.1016/j.actamat.2008.07.029

10. Miura, H., Kobayashi, M., Benjanarasuth, T. Effects of Strain Rate During Multi-Directional Forging on Grain Refinement and Mechanical Properties of AZ80Mg Alloy Materials Transactions 57 (9) 2016: pp. 1418-1423. http://doi.org/10.2320/matertrans.MH201504

11. Xing, J., Yang, X., Miura, H., Sakai, T. Superplasticity of Fine-Grained Magnesium Alloy AZ31 Processed by MultiDirectional Forging Materials Transactions 48 (6) 2007: pp. $1406-1411$.
http://doi.org/10.2320/matertrans.L-MRA2007839

12. Pérez-Prado, M.T., Valle, D., Ruano, O.A. Grain Refinement of Mg-Al-Zn Alloys via Accumulative Roll Bonding Scripta Materialia 51 (11) 2004: pp. $1093-1097$. https://doi.org/10.1016/j.scriptamat.2004.07.028

13. Tsuji, N., Saito, Y., Utsunomiya, H., Tanigawa, S. UltraFine Grained Bulk Steel Produced by Accumulative RollBonding (ARB) Process Scripta Materialia 40 (7) 1999: pp. $795-800$. https://doi.org/10.1016/S1359-6462(99)00015-9

14. Jeppsson, J., Ågren, J., Hillert, M. Modified Mean Field Models of Normal Grain Growth Acta Materialia 56 (18) 2008: pp. $5188-5201$. https://doi.org/10.1016/j.actamat.2008.06.034

15. Jung, S.H., Kang, S.J.L. Repetitive Grain Growth Behavior with Increasing Temperature and Grain Boundary Roughening in A Model Nickel System Acta Materialia 69 (5) 2014: pp. $283-291$. https://doi.org/10.1016/j.actamat.2014.02.016

16. Zhou, T.H., Gheribi, A.E., Zurob, H.S. Austenite Particle Coarsening and Delta-Ferrite Grain Growth in Model Fe-Al Alloy Canadian Metallurgical Quarterly 52 (1) 2013: pp. 90-97.

http://dx.doi.org/10.1179/1879139512Y.0000000037

17. Konkova, T., Mironov, S., Korznikov, A., Korznikova, G., Myshlyaev, M.M., Semiatin, S.L. Grain Growth during Annealing of Cryogenically-Rolled Cu-30Zn Brass Journal of Alloys \& Compounds 666 2016: pp. $170-177$. https://doi.org/10.1016/j.jallcom.2016.01.097

18. Tripathi, A., Samajdar, I., Nie, J.F., Tewari, A. Study of Grain Structure Evolution during Annealing of A Twin-RollCast Mg Alloy Materials Characterization 114 2016: pp. $157-165$. https://doi.org/10.1016/j.matchar.2016.02.019

19. Henseler, R., Herrmann, M., Niethammer, B., Velázquez, J.J.L. A Kinetic Model for Grain Growth Kinetic \& Related Models 4 (1) 2017: pp. 591-617. https://doi.org/10.3934/krm.2008.1.591

20. Pérez-Prado, M.T., Ruano, O.A. Texture Evolution during Grain Growth in Annealed MG AZ61 Alloy Scripta Materialia 48 (1) 2003: pp. 59-64. https://doi.org/10.1016/S1359-6462(02)00346-9

21. Kotan, H., Saber, M., Koch, C.C., Scattergood, R.O. Effect of Annealing on Microstructure, Grain Growth, and Hardness of Nanocrystalline Fe-Ni Alloys Prepared by Mechanical Alloying Materials Science \& Engineering A 552 (34) 2012: pp. 310-315. https://doi.org/10.1016/j.msea.2012.05.045

22. Sellars, C.M., Whiteman, J.A. Recrystallization and Grain Growth in Hot Rolling Metal Science $13(3-4)$ 1979: pp. $187-94$. http://dx.doi.org/10.1179/msc.1979.13.3-4.187

23. Devadas, C., Samarasekera, I.V., Hawbolt, B. The Thermal and Mertallurgical State of Steel Strip During Hot Rolling: Part II. Factors Influencing Rolling Loads Metallurgical Transactions A 22 (2) 1991: pp. 321-333. https://doi.org/10.1007/BF02656802 